Ethiopian Journal of Environmental Studies \& Management 7(4): 379 - 388, 2014

ISSN:1998-0507

doi: http://dx.doi.org/10.4314/ejesm.v7i4.5

Submitted: March 21, 2014

Accepted: June 14, 2014

\title{
A STUDY OF DRY MATTER PARTITIONING AND CONCENTRATION IN GRAIN AMARANTH (Amaranthus cruentus)
}

\author{
EJIEJI, C. J., AJIBOYE, 0., AFOLABI, A. A. AND *ADENIRAN, K. A. \\ Department of Agricultural and Biosystems Engineering, University of Ilorin, Ilorin, Nigeria
}

\begin{abstract}
Dry matter partitioning and dry matter concentration were studied for nine weeks in potted grain amaranth (Amaranthus cruentus) grown under three levels, respectively, of water and NPK fertilizer applications. The water applications were to 100, 75 and 50\% of field capacity. Those of fertilizer were 100, 75 and $50 \%$ of $90 \mathrm{~kg} / \mathrm{ha}$. Field samples were collected at weekly intervals from the 4th week for the fresh and dry weights analysis of shoot and root. Dry matter concentration was estimated on weight basis as percentage of dry matter in fresh matter. Dry matter concentration and percentage dry matter partitioning to shoot components and to root varied throughout the period of study in all the treatment combinations. Generally, the highest percentage dry matter partitioning to the root was in Week 7 with an average value of $36.6 \%$ for all the treatment combinations. For the leaves the highest values occurred between Weeks 4 and 5 and averaged $65.6 \%$ for all the treatment combinations. For stem plus branches and inflorescence, the highest percentages were observed in Week 9 and averaged $46.5 \%$ and $6.3 \%$ respectively. Dry matter concentration was highest in Week 9 for root, stem plus branches and inflorescence with average values of 25.5, 25.0 and $15.3 \%$ respectively. For the leaves the highest dry matter concentration occurred in Week 8 and averaged $20.5 \%$ for all the treatment combinations. An analysis of variance showed that elapsed time after planting and water application were the main factors affecting dry matter partitioning and dry matter concentration. Fertilizer application had no significant effect. However, fertilizer interaction with time significantly affected dry matter concentration in the roots.
\end{abstract}

Key Words: Amaranthus, growth, dry matter, partitioning

\section{Introduction}

The crop Amaranthus cruentus is an important leafy vegetable of high dietary value and widely consumed in Nigeria (National Horticultural Institute Ibadan, 1987). It is grown as mono crop or intercropped with other staple food crops in traditional farming systems for family consumption and market. It is also an important crop in rain-fed and irrigated vegetable production systems of small scale farmers around urban areas and population centres in the country (Ojo et al., 2011).
Towards improved productivity of the crop, several studies have been carried out on the optimum agronomic practices in relation to plant density, fertilizer application and irrigation (Adebayo and Akanni, 2002; Makinde, 2007; Ejieji and Adeniran, 2009; Makinde et al., 2010). An alternative approach to direct field experimentation would be the use of crop yield simulation models which relate crop production to biophysical and environmental factors. Such models are useful for both research and production planning on a wide scale when 
time or resources are limited for direct field experimentation. They can be powerful tools for investigating the performance of varieties in contrasting environments, soil types, diverse cultural practices and management inputs (Japtap et al., 1993). Two main approaches are recognized in crop growth and yield modelling. The first is empirical estimation using regression equations which relate growth and yield to observed environmental and soil factors. The shortcomings of the approach include limited transportability and applicability beyond the localities and conditions from which observations were derived. The second and better approach is based on simulation of biological systems based on crop physiological principles. That is, using biophysical models. Knowledge of the temporal pattern of dry matter partitioning and dry matter concentration and their relationship with water and fertilizer application would be vital for the development such biophysical models. In the simulation model, dry matter partitioning information would be necessary for allocating dry matter produced to the component parts of the plant while knowledge of dry matter concentration is required in the estimation of fresh weight from dry matter weight (Ejieji and Gowing, 2000). The aim of this study therefore was to investigate the effect of varying levels of water and fertilizer applications on dry matter partitioning and dry matter concentration in a growing A. cruentus. The objective was to identify the significant factors that could be considered in dry matter partitioning and dry matter concentration subroutines of a biophysical crop model for A. cruentus.

\section{Materials and Methods Description of the Project Site}

The study was conducted on the experimental plot close to the Department of Agricultural and Biosytems Engineering,
University of Ilorin, Kwara State, Nigeria located approximately on the latitude $08^{\circ} 30^{\prime}$ $\mathrm{N}$ and longitude $04^{\circ} 35^{\prime} \mathrm{E}$ at an elevation of about $340 \mathrm{~m}$ above mean sea level. Ilorin is in the Southern Guinea Savannah Ecological Zone of Nigeria with annual precipitation of about $1300 \mathrm{~mm}$. The wet season begins towards the end of March and ends in October, with a dry spell in August. The dry season starts in November and ends in March.

\section{Layout and Instrumentation}

The site consisted of a cleared plot $80 \mathrm{~m}^{2}$ in area. A central portion $48 \mathrm{~m}^{2}$ was levelled for the location of the experimental units and instrumentation. Three rain shelters were constructed for shielding the crops from additional precipitation. The shield consisted of bamboo framework with sides and top covering made of thick-gauge transparent plastic sheeting. The covering was put in place only when rainfall was imminent. Pots consisting of plastic buckets 11 litres in volume, with five $6 \mathrm{~mm}$ diameter drainage holes drilled at the bottom, were filled to about $2.5 \mathrm{~cm}$ below the rim with $14.47 \mathrm{~kg}$ of air-dried loamy sand soil at gravimetric water content of $4.34 \%$. The soil, which was sieved with an $8 \mathrm{~mm}$ sieve, was collected from the topsoil of a different plot near the workshop building of the Agricultural and Biosystems Engineering Department. It was mixed thoroughly and samples taken for determination of the textual and chemical properties. The treatments were irrigation water (W) and NPK 15-15-15 fertilizer (F) applications. The watering levels are $100 \%$ water application to field capacity (W1), water application to $75 \%$ of field capacity (W2), and water application to $50 \%$ of field capacity (W3). The levels of fertilizer application denoted by F1, F2 and F3 respectively were 100,75 , and $50 \%$ of 90 $\mathrm{kg} / \mathrm{ha}$ rate adopted from Ojo (1998). The soil water content at field capacity was determined in the laboratory by thoroughly 
wetting a soil-filled pot, covering with plastic sheet and allowing it to drain freely for 2 days. Average percentage water content at field capacity was thereafter gravimetrically determined by sampling at $8 \mathrm{~cm}$ depth intervals to the $16 \mathrm{~cm}$ depth of the pot. A total of 81 pots were used for the study, that is, 9 pots per treatment combination. The pots having $\mathrm{W} 1 \mathrm{~F} 1$ treatment combination were left in the open while the others were randomly assigned, in equal numbers per treatment combination, to the rain shelters. The pots in the open and under the rain were spaced $30 \mathrm{~cm}$ x $30 \mathrm{~cm}$ apart. Meteorological instruments were installed for the observation of weather conditions. The various instruments in the station include: a cup counter anemometer, two rain gauges, two evaporation pans, and a Stevenson screen housing the wet and dry bulb thermometer and maximum and minimum thermometer. Wet and dry bulb temperatures were monitored at three-hourly intervals from 6.00h GMT to $18.00 \mathrm{~h}$ GMT. The rain gauges, maximum and minimum thermometer and the evaporation pans were checked and reset at $9.00 \mathrm{~h}$ GMT daily. Daily wind run was monitored by noting the anemometer, reading at 9.00h GMT.

\section{Crop Management}

About $24 \mathrm{~g}$ of the amaranth seed (accession NH84/453Y) was mixed with about $200 \mathrm{~g}$ of $2 \mathrm{~mm}$ sieved air-dried soil and planted in the pots by broadcasting on $23^{\text {rd }}$ February 2009. The seed germinated $4-6$ days later. Some were transplanted 2 weeks after planting to establish growth uniformity. Three weeks after planting, thinning to two plants per pot was done and fertiliser applied at the stated rates. The soil water content was maintained at field capacity up to the second week after germination after which water stressing was started. The pots were weighed daily and the corresponding change in weight and volume of drainage measured water were used to estimate crop water use. During the period of water stressing, water application was at intervals of two days. Cumulative weight of water lost since last water application was estimated for the respective treatments from the average of three pots and converted to volume by assuming a water density of $1000 \mathrm{~kg} \mathrm{~m}^{-3}$. Thus the volume of water to be replenished was estimated for the treatment combinations. Soil water content determination was also carried out at intervals of two weeks to check the soil water status.

\section{Crop Sampling}

Weekly crop sampling was started four weeks after planting and ended at the ninth week. A pot from each treatment combination was randomly chosen for the purpose. Buckets containing crop to be sampled were well watered to make sampling easy and prevent the roots from breaking from the plant. Crop height was measured using a meter rule and number of leaves per plant was counted. The total fresh weight of the plants was measured using a weighing balance. Each sampled plant was partitioned by cutting into leaves, root and stem plus branches. The weight of each of the components was noted. The fresh matter was oven-dried at $70{ }^{\circ} \mathrm{C}$ for $24 \mathrm{~h}$ to constant weight. The dry weight of each plant component was expressed as a percentage of its fresh weight to obtain the dry matter concentration. The dry weight of the component was also expressed as a percentage of the total plant dry matter to obtain the percentage dry matter partitioning to that component.

\section{Data Analysis}

The data on dry matter partitioning and dry matter concentration obtained for the 9 weeks were subjected to analysis of variance using the following linear response model (2009).

$$
\begin{aligned}
& Y_{i j k l}=\mu+\alpha_{i}+\beta_{j}+(\alpha \beta)_{i j}+\lambda_{k}+(\alpha \lambda)_{i k}+ \\
& (\beta \lambda)_{j k}+(\alpha \beta \lambda)_{i j k}+\varepsilon_{i j k l}
\end{aligned}
$$


$l=1,2 ; \quad i=1,2,3 \quad j=1,2,3 \quad k=4, \ldots, 9$

where $\mathrm{Y}$ is the dependent response variable $\mathrm{m}$ denotes general mean, 1 replication, a water treatment, $\mathrm{b}$ fertilizer treatment and 1 denotes time in weeks after planting. The terms in parenthesis represent interaction effects while e is the error term. The dry matter partitioning and dry matter concentration considered were those of the root, stem plus branches and leaves. The significant terms on the right hand side of Equation (1) were thereafter identified.

\section{Results and Discussion Soil and Weather Conditions}

Physical and chemical analysis of the experimental soil showed that it was a sandy loam (Table 1), moderately acidic and low in organic matter, nitrogen and phosphorous (Table 2). The observed weather conditions (Table 3) indicated that high temperatures, high evaporation rates and low wind speeds prevailed during the study with humid conditions in the last three weeks.

\section{Plant Growth and Development}

Plant height generally increased throughout the period of study (Figure 1a). The increased rate from Week 8 was due to onset of inflorescence. In terms of the economic yield, that is leaf productions before onset of inflorescence, W1F1 was the best (Figure 1b). Leaf production generally increased rapidly between Weeks 4 and 5 peaked around Week 6. The result is in contrast with that of Ejieji and Adeniran (2009). In their study, fertilizer was applied twice, that is, at Weeks 4 and 6. Fresh matter accumulation was therefore most rapid from Week 5 and peaked in Week 7 of their study. Root growth mostly peaked around Week 7 (Figure 1c). The temporal trend of root growth was similar to that of a study of the rooting characteristics of some vegetable and grain crops in a similar environment (Olu and Abubakar 2001).

\section{Dry Matter Partitioning and Dry Matter Concentration}

The highest percentage of dry matter partitioning to the roots averaged $36.6 \%$ for all the treatment combinations and occurred in Week 7 (Figure 2a). The Week coincided with the peak period of root growth (Figure 1c). Dry matter partitioning to the stem plus branches increased throughout the period of study, for all the treatment combinations, from an average value of $16.6 \%$ in Week 4 to an average value of $46.5 \%$ in Week 9. The average value for the leaves was $65.6 \%$ between Weeks 4 and 5 before it steadily declined to $25.1 \%$ in Week 9 (Figure 2c). The ending of maximal dry matter partitioning to the leaves in Week 5 coincided with the end of period of most rapid rate of leaf production (Figure $1 b$ ). The average percentage of dry matter partitioning to inflorescence in Week 9 was $6.3 \%$. Generally, the period of most rapid canopy growth and expansion which was between Weeks 4 and 5, was accompanied by slight reduction in dry matter concentration compared with Week 4 values. The reductions were, on the average, from 14.5 to $12.2 \%, 10.0$ to $9.1 \%$ and 15.0 to $12.7 \%$ for the roots, stem plus branches and leaves respectively. Thereafter dry matter concentration increased to average values of $25.5 \%$ and $25.0 \%$ for roots and stem plus branches respectively in Week 9. In the case of the leaves, it increased to an average of $20.5 \%$ in Week 8 followed by a decline to $18.9 \%$ in Week 9 (Figure 3c). The period of decline coincided with that of initiation and development of inflorescence. At the end of Week 9, the dry matter concentration in inflorescence was $15.3 \%$ on the average. 
Effects Water and Fertilizer Applications and Time on Dry Matter Partitioning and Dry Matter Concentration

The complexity of the interrelationships among dry matter partitioning as well as among dry matter concentration and time, fertilizer and water applications was manifest in several inter-crossings among the plots in Figures $2 \mathrm{a}-\mathrm{c}$ and $3 \mathrm{a}-\mathrm{c}$. However, the statistical significance of effects of the factors as well that of the adopted linear model for the analysis could be inferred from the p-values shown in Table 4. The appropriateness of the linear model was confirmed by its high coefficients of determination and statistical significance. Time was a significant factor in both dry matter concentration and dry matter partitioning. Water and its interaction with time significantly affected dry matter partitioning to roots and to leaves. Water and water-time interaction also significantly affected dry matter concentration in stem plus branches. Effect of water on dry matter concentration in root and in leaves was not significant except that of water-time interaction. It should be noted that water treatment in this study was a means of controlling soil water status. Effect of fertilizer was not significant on any of the response variables except that of fertilizertime interaction on root dry matter concentration. The limited effect of fertilizer was unexpected because related studies indicated that fresh and dry matter production respond significantly to fertilizer application (Ejieji and Adeniran 2009; Ojeifo et al., 2009; Adewole and Dedeke 2012). Application timing was however different in Ejieji and Adeniran (2009) while timing, amount and fertilizer types were different in the others.

\section{Conclusions and Recommendations}

The study showed that for A. cruentus growing in a sandy loam under high air temperature and high air evaporative demand, elapsed time after planting and soil water status were the main factors affecting dry matter partitioning and dry matter concentration. Fertilizer application had no significant effect. However, fertilizer interaction with time significantly affected dry matter concentration in the roots. Because of several reported significant response of dry and fresh matter accumulation in the crop to varying fertilizer types and application schedules, further investigation of fertilization effects is suggested. A linear model was found to adequately represent the relationship between the dependent response variables (that is, dry matter portioning and dry matter concentration) and the factors (water and fertilizer applications) in this study. The results of the study should be useful in developing subroutines for dry matter partitioning and dry matter accumulation for a biophysical simulation model for growth, development and yield of $A$. cruentus. They would also be useful in planning of related studies. Replication of this study under lower temperature and more humid conditions of the rainy season may be necessary to ascertain the general applicability of its main conclusions.

\section{Acknowledgement}

The authors are grateful to Prof. F. A. Oladele, Department of Plant Biology, University of Ilorin for many useful suggestions during the study. They are indebted to Prof. E. T. Jolayemi and Miss R. Akanbi both of Department of Statistics, University of Ilorin, Ilorin for assistance rendered in the statistical analysis of the results of the study.

\section{References}

Adebayo, O. and Akanni, A. (2002). Effect of organic manure and spacing on yield and yield components of Amaranthus cruentus. In: Proceedings of Horticultural Society of Nigeria Conference, 14th - 18th April 2002, Ibadan Nigeria, pp. 85 - 90. 
Adewole, M.B. and Dedeke, O.A. (2012). Growth performance, yield and nutritional quality of Amaranthus cruentus L. under repeated application of poultry manures. Ife Journal of Technology, 14(2): 345 - 355

Ejieji, C.J. and Adeniran, K.A. (2009). Effects of water and fertilizer stress on the yield, fresh and dry matter production of grain Amaranth (Amaranthus cruentus). Australian Journal of Agricultural Engineering, 1(1): 18-24.

Ejieji, C.J. and Gowing, J.W. (2000). A dynamic model for responsive scheduling of potato irrigation based on simulated water-use and yield. Journal of Agricultural Science, 135: 161 - 171.

Japtap, S.S., Mornu, M. and Kang, B.T. (1993). Simulation of growth, development and yield of maize in the transition zone of Nigeria. Agricultural Systems, 41: 215 - 229.

Makinde, E.A. (2007). Evaluation of organomineral fertilizer on growth yield and quality of Amaranthus cruentus on two soil types in Lagos State Nigeria. Unpublished thesis (Ph.D.), University of Ibadan.

Makinde, E.A., Ayeni, L.S. and Ojeniyi, S.O. (2010). Morphological characteristics of Amaranthus cruentus as influenced by kola pod husk, organomineral and NPK fertilizers in Southwest Nigeria. NewYork Science Journal, 3(5):130134.

Montgomery, D.C. (2009). Design and analysis of experiments, John Wiley and Sons, Inc. $7^{\text {th }}$ edition, pp. 265
National Horticultural Research Institute (1987). Advances in fruit and Vegetable Researches at NIHORT (1976-1987), NIHORT Publication Press, PMB 5432, Ibadan.

National Weather Service (2013). Relative humidity and dew point temperature from temperature and wet bulb temperature. Available from: http://www.srh.noaa.gov/images/epz/wx calc/rhTdFromWetBulb.pdf [Accessed 03/03/13 ]

Ojeifo, I.M., Nnaji, G.U. and Nnoka, S.C. (2009). The response of corridor-grown. Amaranthus cruentus L. to liquid organic fertiliser. Journal of Research in National Development, 7(1): Available at:http://www.transcampus.org/JORINDV7J un2009/JournalsV7NO1Jun2009 [Accessed 03/03/13 ]

Ojo, O.D. (1998). Growth and yield of Celosia argentea in response to a balanced NPK fertilizer. Journal of Vegetable Crop Production, 4(1): 77-83.

Ojo, O. D., Connaughton, M., Kintomo, A.A., Olajide-Taiwo, L.O. and Afolayan, S.O. (2011). Assessment of irrigation systems for dry season vegetable production in urban and peri-urban zones of Ibadan and Lagos, Southwestern Nigeria. African Journal of Agricultural Research, 6(2): 236 - 243.

Olu, O.E.A. and Abubakar, L. (2001). Modelling root depth development with time under some crop and tillage management systems. Journal of Agricultural Research and Development, 1: $51-65$.

Table 1: Physical properties of the experimental soil

\begin{tabular}{|c|c|c|c|c|c|c|}
\hline $\begin{array}{l}\text { Gravel } \\
>2 \mathrm{~mm} \\
(\mathrm{~kg} / 100 \mathrm{~kg})\end{array}$ & $\begin{array}{l}\text { Sand } \\
2 \text { to } .02 \mathrm{~mm} \\
(\%)\end{array}$ & $\begin{array}{l}\text { Silt } \\
.02 \text { to } .002 \mathrm{~mm} \\
(\%)\end{array}$ & $\begin{array}{l}\text { Clay } \\
<.002 \mathrm{~mm} \\
(\%)\end{array}$ & $\begin{array}{l}* \text { Bulk } \\
\text { Density } \\
\left(\mathrm{kg} \mathrm{m}^{-3}\right)\end{array}$ & $\begin{array}{l}\text { Textural } \\
\text { class }\end{array}$ & $\begin{array}{l}* \text { Water con- } \\
\text { tent at field } \\
\text { capacity } \\
(\%)\end{array}$ \\
\hline 14.57 & 81.71 & 10.47 & 7.60 & 1320.80 & $\begin{array}{l}\text { Sandy } \\
\text { loam }\end{array}$ & 21.36 \\
\hline
\end{tabular}

$*=$ Average value in the pots after filling 
Table 2: Chemical properties of the experimental soil

\begin{tabular}{lc}
\hline Soil property & Composition \\
\hline $\mathrm{pH}$ & 5.45 \\
Organic matter $(\%)$ & 1.29 \\
Total Nitrogen $(\%)$ & 1.40 \\
Available Phosphorus (mg/kg) & 3.75 \\
Exchangeable absorption ratio & 11.98 \\
Exchangeable cations (cmol/kg soil) & \\
$\mathrm{Ca} 2+$ & 1.56 \\
$\mathrm{Mg} 2+$ & 1.31 \\
$\mathrm{Na}+$ & 1.14 \\
$\mathrm{~K}+$ & 2.27 \\
\hline
\end{tabular}

Table 3. Average meteorological conditions during the study (February to April, 2009)

\begin{tabular}{llllllll}
\hline $\begin{array}{l}\text { Weeks } \\
\text { after } \\
\text { planting }\end{array}$ & Period & \multicolumn{2}{l}{$\begin{array}{l}\text { Temperature } \\
\left({ }^{\circ} \mathrm{C}\right)\end{array}$} & $\begin{array}{l}\text { Relative } \\
\text { humidity }\end{array}$ & $\begin{array}{l}\text { Wind run } \\
(\mathrm{km} / \text { day })\end{array}$ & $\begin{array}{l}\text { Pan } \\
\text { evaporation } \\
(\mathrm{mm} / \text { day })\end{array}$ & $\begin{array}{l}\text { Rainfall } \\
(\mathrm{mm})\end{array}$ \\
\cline { 2 - 5 } & & Max & Min & & & & \\
\hline 1 & $23 / 02-01 / 03$ & 38.4 & 25.2 & 64.5 & 42.71 & 6.1 & nil \\
2 & $02 / 03-08 / 03$ & 38.1 & 26.1 & 60.2 & 58.82 & 6.1 & nil \\
3 & $09 / 03-15 / 03$ & 37.6 & 25.1 & 63.3 & 38.87 & 5.9 & nil \\
4 & $16 / 03-22 / 03$ & 36.5 & 25.5 & 60.4 & 81.45 & 6.4 & nil \\
5 & $23 / 03-29 / 03$ & 38.2 & 26.0 & 67.5 & 62.26 & 6.4 & nil \\
6 & $30 / 03-05 / 04$ & 37.1 & 22.5 & 67.4 & 48.84 & 5.1 & 21.7 \\
7 & $06 / 04-12 / 04$ & 35.6 & 24.1 & 77.8 & 58.08 & 5.7 & 51.7 \\
8 & $13 / 04-19 / 04$ & 32.6 & 23.7 & 78.5 & 39.28 & 6.3 & 27.2 \\
9 & $20 / 04-26 / 04$ & 35.1 & 23.3 & 79.7 & 35.44 & 6.1 & 30.6 \\
\hline
\end{tabular}

* computed using observed wet and dry bulb temperatures (National Weather Service, 2013)

Table 4. ANOVA p-values for the factors affecting dry matter partitioning and dry matter concentration, including $\mathrm{p}$-values for the adopted linear model and the coefficients of determination of the model. ( $\mathrm{p}$-values more than 0.05 are not significant)

\begin{tabular}{|c|c|c|c|c|c|c|c|c|c|c|}
\hline $\begin{array}{l}\text { Plant } \\
\text { component }\end{array}$ & $\mu$ & $\lambda$ & $\alpha$ & $\beta$ & $(\lambda \alpha)$ & $(\lambda \beta)$ & $(\alpha \beta)$ & $(\alpha \beta \lambda)$ & Model & $\mathrm{R}^{2}$ \\
\hline \multicolumn{11}{|c|}{ Dry matter partitioning } \\
\hline Root & 0.000 & 0.000 & 0.035 & 0.734 & 0.017 & 0.813 & 0.914 & 0.130 & 0.000 & 0.885 \\
\hline Stem + & & & & & & & & & & \\
\hline Branches & 0.000 & 0.000 & 0.457 & 0.142 & 0.335 & 0.926 & 0.437 & 0.335 & 0.000 & 0.954 \\
\hline Leaves & 0.000 & 0.000 & 0.007 & 0.722 & 0.027 & 0.500 & 0.370 & 0.258 & 0.000 & 0.973 \\
\hline \multicolumn{11}{|c|}{ Dry matter concentration } \\
\hline Root & 0.000 & 0.000 & 0.149 & 0.293 & 0.001 & 0.001 & 0.211 & 0.063 & 0.000 & 0.908 \\
\hline $\begin{array}{l}\text { Stem + } \\
\text { Branches }\end{array}$ & 0000 & 0000 & 0007 & 0849 & 0040 & 0084 & 0.494 & 0875 & 0000 & 0963 \\
\hline Leaves & 0.000 & 0.000 & 0.118 & 0.504 & 0.000 & 0.247 & 0.737 & 0.278 & 0.000 & 0.879 \\
\hline
\end{tabular}



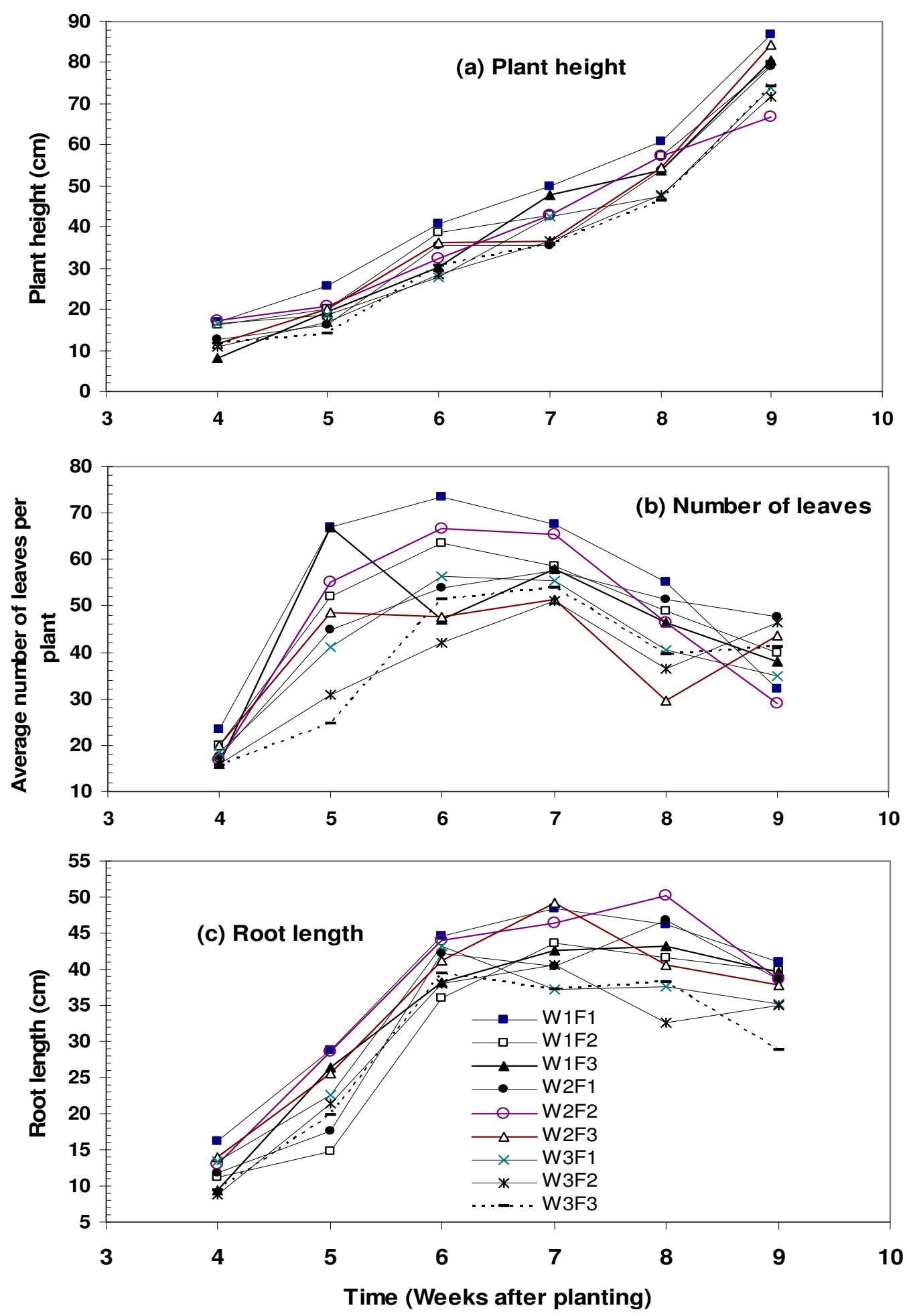

Figure 1. Plant growth and development indicators in the various weeks: (a) height (b) number of leaves (c) root length. (W1, W2 and W3 respectively represent water application to 100, 75 and $50 \%$ of field capacity. F1, F2, and F3 respectively denote 100,75 and $50 \%$ of $90 \mathrm{~kg} / \mathrm{ha} \mathrm{NPK}$ fertilizer application). 

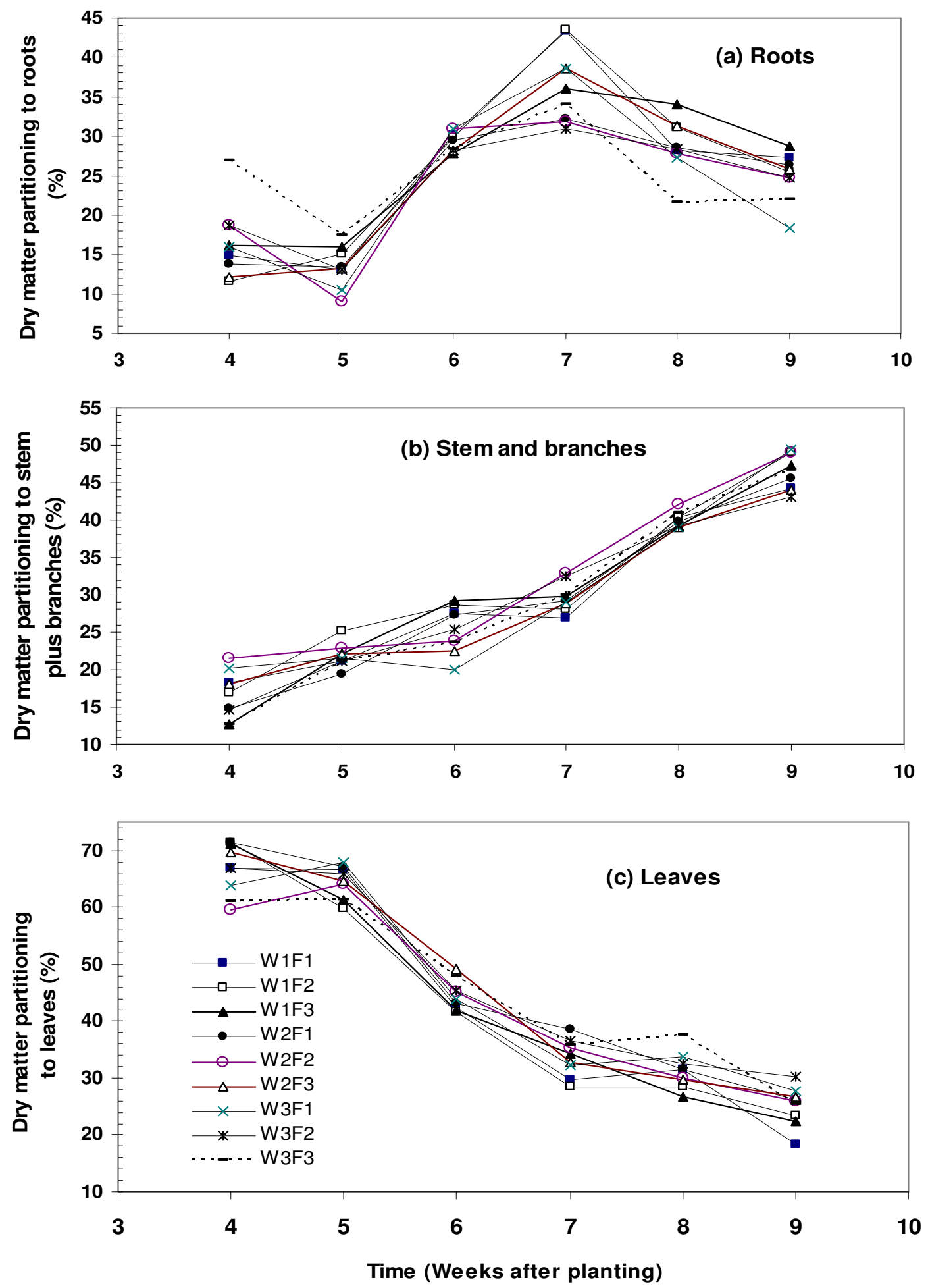

Figure 2 Percentages of dry matter partitioning to the (a) roots, (b) stem plus branches and (c) leaves in the various weeks. (W1, W2 and W3 respectively represent water application to 100, 75 and $50 \%$ of field capacity. F1, F2, and F3 respectively denote 100,75 and $50 \%$ of $90 \mathrm{~kg} / \mathrm{ha} \mathrm{NPK}$ fertilizer application). 

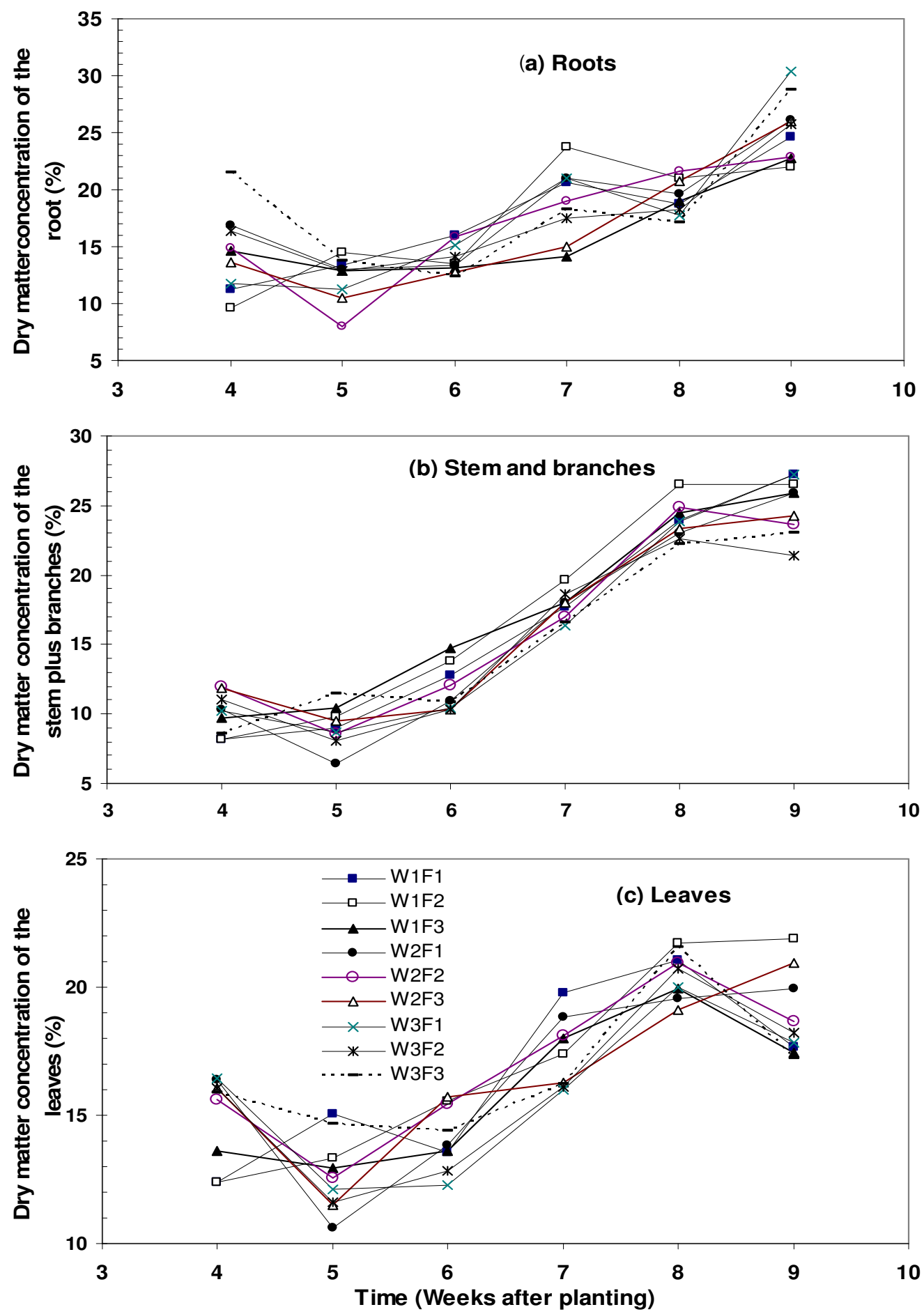

Figure 3 Dry matter concentrations of the (a) roots, (b) stem plus branches and (c) leaves in the various weeks. (W1, W2 and W3 respectively represent water application to 100, 75 and 50\% of field capacity. F1, F2, and F3 respectively denote 100, 75 and $50 \%$ of $90 \mathrm{~kg} / \mathrm{ha} \mathrm{NPK}$ fertilizer application). 